\title{
Los efectos de la crisis en la Argentina de la Post Convertbilidad. La racionalidad económica en discusión
}

\author{
Alejandro Balazote * \\ Daniel Piccinini **
}

\section{Resumen}

De las repetidas crisis que conoció la Argentina en los últimos 35 años y particularmente de la hiperinflación de 1989, surgió el programa neoliberal que la ató durante los años 90 a un sistema de Convertibilidad del peso a la par del dólar, abriendo su mercado a las exportaciones, privatizando sus empresas públicas, expandiendo aún más su deuda externa y dando lugar a un modelo ejemplar del pensamiento económico ortodoxo. En 2001 una insurrección popular acabó por desmoronar a ese modelo y marcó nuevas condiciones de gobernabilidad. La economía fue redireccionada y a pesar de la oposición de algunos sectores, el país entró en un crecimiento sin precedentes. Eso no impidió que pasase a ser el peor ejemplo para los referentes de la economía global. Sin embargo la cuarentena financiera a la que fue confinado lo preservó de los peores efectos de la crisis de 2008. Se analizan en este artículo algunas derivaciones de esa circunstancia y los aciertos y los déficits de la actual gestión para aprovechar las oportunidades de una experiencia que cuestiona los parámetros de la racionalidad dominante en el discurso económico normativo.

Palabras-clave: crisis financiera, medidas contraciclicas, racionalidad económica.

Doctor de la Universidad de Buenos Aires. Profesor Titular de la Universidad de Buenos Aires. Profesor Titular de la Universidad Nacional de Lujan. Presidente de la Comisión de Estudios Posdoctorales de la Facultad de Filosofía y Letras de la Universidad de Buenos Aires. Endereço eletrônico: abalazot@fibertel.com.ar.

***ar Profesor Titular de la República Argentina en la Universidad de La Plata, Profesor Asociado en Geografía Social Argentina de la Universidad de Buenos Aires y Profesor Adjunto de Sociología General en la Universidad de Luján. Endereço eletrônico: piccinini@filo.uba.ar. 


\section{Introducción}

mediados de septiembre de 2008 Lehman Brothers, cuarto
lbanco de inversión de Estados Unidos, declaró su quiebra tras 158 años de actividad. La caída de esta institución y de otras que le precedieron, tendría importantes consecuencias para el sistema financiero mundial que no pudieron ser evitadas pese a las medidas en apoyo a la banca impulsadas por la FED.

El colapso de la burbuja inmobiliaria iniciada dos años antes debido al quiebre de los pagos en hipotecas de alto riesgo (subprime) debido al aumento de las tasas de interés y la sobre valoración de los activos comenzó a manifestarse dramáticamente a inicios de 2008, impactando primeramente en el sistema financiero estadounidense, y luego en el internacional. Finalmente las consecuencias de esta crisis afectaron la economía real observándose grandes caídas en la producción y en la demanda mundial.

Los elevados precios de las commodities de años anteriores se desplomaron y los países proveedores de alimentos y energía al sistema económico mundial vieron reducir drásticamente sus ingresos y profundamente alterada su matriz exportadora. A la disminución de ingresos proveniente por la caída internacional del precio de las materias primas se sumó la baja ocasionada por la menor demanda de los mismos.

En este trabajo nos proponemos analizar el impacto de la crisis económica internacional en la economía argentina, para ello iniciamos nuestro análisis a partir de la implementación de la convertibilidad, la crisis que aconteció socioeconómica de los años 2001-2002 y la implementación de un nuevo modelo económico. Abordaremos el rol del Estado ante la baja de los patrones de actividad y los dispositivos socioeconómicos implementados ${ }^{1}$.

1 Este artículo es una versión levemente modificada del trabajo "La crisis global. Un nuevo escenario para discutir la racionalidad económica: El caso argentino" presentado en el VII Workshop. Empresa, Empresários e Sociedade realizado en Florianopolis del 25 al 28 de mayo de 2010. 


\section{La Convertibilidad}

La crisis mundial de 2008 encontró a la Argentina con una vívida memoria de sus propias crisis nacionales, la experiencia de la sociedad argentina en procesar complejos escenarios económicos constituyó sin duda un matiz diferencial con otros países emergentes. Es por lo tanto crucial recordar rápidamente recientes antecedentes para interpretar la forma en que hoy se enfrenta la crisis.

La historia económica de Argentina registra un largo periodo de inflación crónica y creciente que comienza a mediados del siglo pasado y se interrumpe con el régimen de Convertibilidad monetaria fija que se instaura casi dos años después de la hiperinflación desencadenada en $1989^{2}$. La convertibilidad del peso, es decir, la fijación por ley del tipo de cambio, garantizaba a los tenedores la obligación del Banco Central de vender dólares de sus reservas a la paridad establecida de uno a uno ${ }^{3}$, significó por su parte, desde comienzos de 1991, un intento de poner fin a dicha dinámica sustrayendo el valor del dinero de la puja distributiva y el conflicto social.

Luego de una fluctuante trayectoria la Convertibilidad, acogida inicialmente de manera favorable por los más diversos sectores sociales y productivos como salida a la hiperinflación, acabaría finalmente sus días a comienzos del 2002 cuando la reforma de la estructura económica acorde a los preceptos neoliberales que ella misma había facilitado dio lugar a una situación insostenible tanto en lo económico como en lo financiero. Se abriría entonces una nueva etapa de la política económica argentina cuyos tanteos se

2 Dichos procesos hiperinflacionarios constituyeron una feroz ofensiva del capital contra el trabajo, un proceso de expropiación extraordinaria o, más precisamente, de "acumulación originaria reiterada".

3 A partir del mes de marzo de 1991 el Banco Central vende sus dólares respaldando ese valor con sus propias reservas de oro, divisas y títulos públicos en moneda extranjera a precio de mercado. A partir de ese momento se establece un régimen bimonetario que permite el empleo de ambas monedas en las transacciones corrientes y se elimina el sistema de indexación por inflación que hasta entonces era usual en la celebración de los contratos. Por otro lado el Banco Central dejaba de ser prestamista de última instancia de los bancos comerciales en dificultades aunque seguía estableciendo sus encajes. 
desarrollaron en un ciclo expansivo que se interrumpe abruptamente con la actual crisis mundial.

Simultáneamente con la convertibilidad se llevaron a cabo importantes reformas estructurales, desregulaciones y privatizaciones, tendientes a la apertura de la economía. La reforma del estado y la apertura económica provocaron cambios sustanciales en la demanda agregada.

La implementación del modelo económico de la década del 90 excedía pues la mera configuración de reglas cambiarias. La convertibilidad cambiaria fue acompañada por la desregulación los servicios, la apertura económica vía disminución de aranceles la reforma del Estado y el proceso de privatizaciones.

El consenso inicial de amplios sectores de la población debe entenderse a partir de los estragos sociales que causaron los procesos inflacionarios e hiperinflacionarios que traumáticamente sirvieron como mecanismo de transferencia de recursos hacia los sectores más concentrados de la economía. Dichos consensos son pues comprensibles considerando la traumática perspectiva de la economía nacional desde la hiperinflación de 1989 cuyo fantasma sigue sobrevolando en la memoria colectiva.

La inflación crónica que afectó a la última mitad del siglo pasado había llevado a la producción volcada al mercado interno - que representaba alrededor del $85 \%$ del producto nacional de bienes- a un ritmo de expansión que se fue haciendo tan lento que al cabo terminó por prácticamente paralizar toda actividad. El crecimiento productivo nacional se fue haciendo tan lento que, en el contexto de las disputas sociales por el cada vez más escaso ingreso, terminó acelerando la inflación. Lo cierto es que en ese marco inflacionario las decisiones en materia de inversión tendían a hacerse a plazos cada vez más cortos y por lo tanto se fueron alcanzando así niveles mínimos de crecimiento hasta llegar al estancamiento, con las inevitables consecuencias en términos de puja social por la distribución del ingreso. El régimen de convertibilidad vino a detener esa dinámica estabilizando efectivamente precios y salarios. Es sin embargo necesario advertir que en los hechos éstos últimos ya habían venido cediendo su participación en el ingreso total a lo largo de aquel ciclo 
y esa caída se precipitó aun más con la hiperinflación que facilitó la aceptación generalizada de la nueva salida monetaria.

En ese contexto, las condiciones estaban dadas para intentar de una vez por todas lo que los sectores económicos más concentrados venían pregonando desde mediados de los años 50 y sobre todo luego de la crisis de 1975: una profunda reforma de la estructura económica que sacrificara la esclerotizada industria nacional orientada al mercado interno y se volcara la mercado externo aprovechando los recursos naturales existentes y, eventualmente, la baratura que se había alcanzado en el precio de la mano de obra; aún si, en un primer momento, una tasa de cambio que sobrevaluaba al peso para atraer inversiones financieras hacía de la Argentina un mercado importador antes que exportador. El programa económico de fines del siglo XX utilizó entonces la traumática experiencia inflacionaria de las décadas anteriores para alcanzar, por vía de la estabilidad monetaria que permitía el régimen de convertibilidad, una reestructuración productiva que, a la sazón, coincidía con las recomendaciones neoliberales del gobierno financiero mundial. La Argentina fue de ese modo el alumno dilecto del Consenso de Washington, lo que permitió que, al menos en un principio, los organismos multilaterales de crédito estuvieran ampliamente dispuestos a apoyar la experiencia.

Desde 1991, año de implementación del nuevo sistema monetario, hasta mediados de 1998, el PBI revirtió las anteriores tasas negativas con valores que oscilaron entre alrededor del $9 \%$ y el $5 \%$ anual, con la excepción de 1995 cuyos valores negativos reflejaron el impacto en el ámbito local de la crisis mexicana. Pero a partir del último trimestre de 1998 las cifras siempre estarían por debajo del cero. La performance positiva de los primeros años fue el producto de un incremento de las inversiones extranjeras directas que aprovecharon las privatizaciones a precio vil de las actividades productivas y de servicios que venía prestando el Estado. La reducción de los aranceles permitió por su lado abrir el mercado local a productos contra los cuales la industria nacional caracterizada por su escasa productividad y lastrada ahora también por el tipo de cambio, no podía competir, acarreando consigo un incremento del desempleo que tocaría techo con la crisis de 1995. Pero, al mismo tiempo, 
esto permitía al capital productivo más concentrado una mayor accesibilidad a las nuevas tecnologías extranjeras y con ello un salto en la productividad que no tenía antecedentes en los últimos veinticinco años. Así, al menos en un comienzo, la nueva política monetaria conformó a los sectores productivos más concentrados tanto nacionales como extranjeros.

El encarecimiento relativo a nivel internacional de la mano de obra por efecto de la sobrevaluación del peso que se sostenía en el apoyo del crédito internacional y el ingreso de inversiones financieras atraídas por las altas tasas ofrecidas, permitió una sustitución de mano de obra por tecnología en las actividades con mercados locales cautivos - como los servicios privatizados- o con inserción en los mercados externos -como la agricultura que, junto a la extracción de petróleo se transformaron en los rubros casi exclusivos de las exportaciones- ${ }^{4}$. Mientras tanto, la quiebra de las pequeñas empresas y la flexibilización de las relaciones laborales concurrían a incrementar la desocupación y la depresión del salario en las restantes actividades. En consecuencia, la distribución del ingreso conoció una polarización formidable que tornó a la estructura nacional del ingreso comparable a la del resto del continente. Se agregó a esto, a partir de mediados de la década de los 90 , la reducción sostenida del gasto social inducida por la necesidad de mantener el pago de la deuda pública tratando de mantener al mismo tiempo el superávit fiscal. El conjunto de todos estos factores llevó a un inédito crecimiento de la pobreza que al deprimir la demanda interna retroalimentaba

4 El coeficiente de apertura (suma de las exportaciones e importaciones sobre el $\mathrm{PBI}$ ) de la Argentina que era de alrededor del 15\% hacia la primera mitad de los 70 y no llegaba al $12 \%$ en 1991 cuando aún se sentían los efectos de la hiperinflación, alcanza casi el $19 \%$ antes de la recesión que comienza en 1998. Esto incremento del comercio exterior sólo puede ser vinculado muy relativamente con el comportamiento expansivo del modelo ya que esa creciente apertura implicó casi siempre saldos comerciales notoriamente negativos, con lo cual sólo las inversiones extranjeras directas de los primeros años y el endeudamiento posterior aseguraban el balance de divisas que permitía respaldar la convertibilidad. Tanto más que los aportes iniciales de las inversiones extranjeras se convirtieron rápidamente en lo contrario por efecto de las crecientes remesas de utilidades, las altas tasas de intereses pagadas a los préstamos tomados en el extranjero y a su fuerte tendencia a importar servicios, equipos e insumos. 
aceleradamente su expansión con lo cual la situación política no tardaría mucho en volverse literalmente explosiva.

En el año 1999 se produce el cambio de signo político en el gobierno nacional que se preocupó por dejar en claro durante su campaña electoral que no habría modificaciones en relación al modelo económico implementado. Las condiciones macroeconómicas imperantes hicieron que sus primeras medidas consistieran en un fuerte ajuste que implicó la suba de impuestos y el recorte del gasto social. De esta manera, se agudizaron los conflictos sociales y la caída de la actividad económica se vio plasmada en la disminución del PBI.

Los inversores extranjeros de fondos especulativos -gracias a los cuales se mantenía un nivel de reservas suficiente como para responder a la conversión del peso- comenzaron a percibir poco realista el precio de la moneda argentina en ese contexto de depresión y decidieran entonces retirar sus posiciones del país. A finales del año 2000 el Estado empezó a mostrar dificultades para pagar la deuda. Para evitar que sobreviniera la estampida de los inversores externos y de los ahorristas locales se recurrió a un gigantesco préstamo por casi 40 mil millones de dólares otorgado en conjunto por el FMI, el Banco Mundial, el BID, un grupo de bancos privados, el gobierno de España y las administradoras argentinas de fondos previsionales que se conoció como el "blindaje" de las reservas del Tesoro. Aunque de esa suma sólo la mitad sería "dinero fresco" y, a su vez, sólo la mitad se iría entregando paulatinamente a lo largo del año siguiente. En esas condiciones el "blindaje" se horadó rápidamente y las fugas de divisas empezaron efectivamente a registrarse desde marzo de 2001.

\section{La crisis del gobierno de la Alianza}

Durante los primeros meses del 2001 la crisis económica obligó a un ajuste más profundo que desembocó en el regreso de Cavallo al Ministerio de Economía quien retomó enseguida el curso de los ajustes permanentes -un nuevo impuesto al cheque en mayo, un recorte presupuestario en junio y, finalmente, la denominada "ley 
de déficit cero" en julio y debió negociar una amplia reestructuración de deuda externa -el llamado "megacanje" 5 , un masivo canje de títulos que ponía nuevamente en evidencia la situación de default y crisis financiera inminente.

La mencionada ley de déficit cero, una medida destinada a demostrar disciplina fiscal ante los acreedores externos, es particularmente relevante en este contexto. En efecto, la supresión del déficit público primario implicaba un recorte móvil de salarios nominales del sector público y de jubilaciones, fijado inicialmente en el $13 \%$, la supresión de los incentivos y otras partidas complementarias destinadas a sueldos en la educación, recortes en los subsidios de desempleo y en los presupuestos provinciales, etc. Este nuevo ajuste es particularmente relevante, decimos, porque desataría la oleada final de luchas que culminó en diciembre con el derrumbe de la convertibilidad. La resistencia de los ajustados se mostraría así de hecho, como el verdadero límite del ajuste y de la propia convertibilidad (BONNET, 2002).

A pesar de todos esos esfuerzos que incrementaban rápidamente la deuda externa, la fuga de capitales no se detuvo y antes de que finalizara el año, el modelo de Convertibilidad ya había colapsado dejando un pasivo decididamente incobrable.

Casi 30 mil millones de dólares habían emigrado a lo largo del 2001, suma que duplicaba las reservas con las que contaba el Banco Central al finalizar el año que, en consecuencia, no podía respaldar los casi 50 mil millones que estaban depositados en los bancos. La Comisión legislativa investigadora que se conformó para investigar esa fuga de divisas estableció que alrededor de 20 mil millones fueron exteriorizados por las cien primeras empresas localizadas en el país que se ocupaban de actividades no financieras y entre las cuales ocupaban un rol destacado las empresas de servicios que habían sido privatizadas y eran controladas por grupos extranjeros que veían que la paridad entre el peso y el dólar estaba condenada a corto plazo y, con ello, sus posibilidades de negocios (Comisión

5 Para tratar de llevar calma a los inversionistas el gobierno decidió rescatar con el apoyo del FMI los bonos de deuda externa de más o menos inminente vencimiento, cambiándolos contra otros con vencimientos de entre 5 y 17 años. 
Especial Investigadora de la Cámara de Diputados sobre Fuga de Divisas de la Argentina, 2005).

El sistema de Convertibilidad Monetaria se había vuelto insostenible y el FMI ya no estaba en condiciones de seguir alimentando una caja que se tornaba irremediablemente deficitaria, tanto menos que su propia caja ya se perfilaba hacia la quiebra tal como se lo reconociera un par de años más tarde. Comenzaría entonces una corrida bancaria generalizada, los depositantes retiraban sus ahorros a medida que vencían y los tesorizaban o giraban a bancos en el extranjero. Para tranquilizar a los ahorristas se aumentaron al promediar el año los requisitos mínimos de liquidez de los bancos para depósitos con plazos inferiores a un año y, un par de meses después, se sancionó una ley garantizando la devolución de todos los depósitos a plazo fijo en la moneda en que fueron realizados, mientras los bancos locales seguían aumentando las tasas de interés tratando de retenerlos alcanzando de ese modo valores que no eran razonables. En consecuencia el retiro de los depósitos no se detuvo y a principios de diciembre las autoridades pusieron entonces un riguroso límite a las extracciones en efectivo, así como a las transferencias al exterior implementando un "corralito" financiero.

La situación política, que ya era crítica a causa de los efectos sociales que acarreaba el modelo económico en términos de ingresos y desocupación, explotó con esta restricción y días después una insurrección popular forzó la caída del gobierno. La Argentina pasaría las fiestas navideñas del año 2001 en un clima casi insurreccional. Habiendo dimitido el gobierno después del levantamiento que fue sangrientamente reprimido, asume efímeramente Rodriguez Saa (el gobernador de la pequeña provincia de San Luis) y declara la cesación de pagos. Su gobierno duraría menos de una semana siendo reemplazado finalmente por Eduardo Duhalde (vicepresidente durante el gobierno de Carlos Menem).

Después de haber entrado en default y sin recursos para cumplir los compromisos financieros tanto externos como internos, el gobierno reconoció que no podía afrontar el pago a los ahorristas que habían depositado dólares agudizando el descontento y el reclamo de los ahorristas por recuperar sus depósitos. Estos sectores medios confluyeron con el reclamo de sectores populares que 
exigían asistencia para poder sobrevivir después de la gigantesca crisis social. La consigna "piquete y cacerola, la lucha es una sola" sintetizó una alianza que resultó efímera.

La pesificación de pasivos deudas y la emisión de bonos para regularizar los compromisos con los ahorristas fue la estrategia implementada tendiente a descomprimir una coyuntura conflictiva y a diferir las obligaciones financieras.

Finalmente, quienes resultaron más afectados fueron evidentemente los asalariados que vieron licuarse sus ingresos sin ninguna contrapartida, tanto más que durante el primer año de la crisis se congelaron los sueldos.

\section{La Post Convertibilidad}

El sector empresarial vinculado a la producción industrial que, desde mediados de la década anterior, empezaba a ver cada vez más comprometida su situación tanto por el tipo de cambio bajo como por la retracción del mercado interno, participó directamente en la gestión de transición hacia el modelo que suplantaría a la Convertibilidad que ya no podía subsistir si no al precio de una conflictividad social aguda y sostenida. Días antes de la pesificación fue creado el Ministerio de la Producción designándose ministro al representante de la Unión Industrial. Esta institución era, al menos en ese momento, portavoz de aquellas empresas comprometidas en un cambio de rumbo y que a menudo también estaban endeudadas con los bancos locales y eran por lo tanto las más interesadas en la "pesificación asimétrica".

Resuelto ese punto, el sector productivo nacional veía abrirse entonces gracias a la devaluación que significaba la licuación -en este caso no compensada- del costo de la mano de obra y otros insumos básicos, una ventaja competitiva en el mercado externo que les permitiría salir de la recesión que, a esa altura, se había transformado en la más larga de la historia del país. Empezaba así una nueva orientación de los negocios, sobre todo para las firmas más concentradas, hacia la colocación de la producción en los mercados externos y al mismo tiempo un nuevo proceso de 
substitución de importaciones en los bienes de consumo final. La hegemonía que en los 90 habían alcanzado el sector financiero y las empresas de servicios adquiridas por los capitales extranjeros se desplazaba hacia la industria y, por supuesto, también hacia la producción agropecuaria que se encontraba no obstante en un viejo y conocido dilema dada la característica simultánea de bienes transable y bienes salario de su producción.

Efectivamente, el Estado era llamado, por la misma fuerza de las cosas, a jugar un rol regulador activo que hasta ese momento había sido repudiado por todo el establishment económico y político. Así fue que, entre otras cosas, se reintrodujeron los aranceles a la exportación que habían sido derogados al instaurarse la Convertibilidad ya que, de no hacerlo, no sólo se perdía una oportunidad de recaudación necesaria para financiar la compensación a los bancos y aspirar al equilibrio fiscal, sino que además, los precios internacionales se habrían impuesto en el mercado nacional donde los ingresos no hubieron alcanzado para asegurar la subsistencia de la población. Los derechos de exportación (popularmente conocidos como "retenciones") se establecieron con tasas diferenciales según el sector, siendo más elevadas para los combustibles y las actividades agropecuarias más tradicionales que, a más de ser las más competitivas tanto por sus condiciones de producción como por el comportamiento de los precios mundiales en ese momento, estaban más directamente ligadas con el efecto de éstos sobre los del mercado interno.

La recaudación de las retenciones se empezó así a utilizar también para compensar las transacciones internas de algunos productos considerados de importancia en el consumo de la población. Las operaciones entre el sector agropecuario y el de transformación deben hacerse con referencia a un precio oficial de abastecimiento y la brecha entre ese precio y el precio de mercado al momento de la transacción es cubierta por el Estado recurriendo a lo recaudado por derechos de exportación. De ese modo, y recurriendo también a veces a la cupificación de la exportación, se limita al menos parcialmente, y sobre todo en lo referido a los alimentos más masivos, el efecto interno de la valorización en dólares de los productos agropecuarios. De la misma manera, esa carga impositiva se utilizaba 
para intentar desalentar la expansión del monocultivo sojero que, indirectamente, incide en la alimentación popular al desplazar a la producción de alimentos. No obstante, no todo lo recaudado en ese concepto se usaba para el único fin de reducir la brecha entre los precios internacionales y las posibilidades de adquisición en el mercado interno, también permitían subsidiar los precios de determinados productos agroindustriales, dejando además un saldo tanto para el financiamiento de otras políticas sociales de emergencia como para concurrir al superávit fiscal acordado con el FMI a fin de asegurar el pago de la deuda. Pero el sector agropecuario no tenía las mismas necesidades que el sector financiero de recuperar sus préstamos ni encontraba un interés particular en mantener barata la mano de obra dada la escasa incidencia de la misma en su actividad. Las "retenciones" eran por lo tanto percibidas por el sector como una expropiación de su renta del suelo y por lo tanto serían fuertemente resistidas una vez pasada la conmoción política de la crisis del régimen anterior. Sin embargo, la intervención pública debía ir más allá de esta regulación del mercado externo de ciertos alimentos y combustibles, procediéndose también a congelar junto a los salarios, el precio de la energía -aunque compensando a las empresas con la importación sin aranceles de gas oil- y las tarifas de los servicios.

Dada la importancia que había alcanzado el desempleo y la informalidad a lo largo de los últimos años, los nuevos ingresos del Estado financiaban los intentos de restablecer el orden mediante la ampliación de medidas asistenciales. Al asumir Néstor Kirchner la presidencia en 2003 y luego Cristina Kirchner en 2007, las líneas de ruptura que se habían iniciado en el 2002 se fueron profundizando. Así se comenzó a intervenir sistemáticamente en el mercado de divisas mediante la compra de dólares por parte del Banco Central para mantener el tipo de cambio alto, lo que además permitió reforzar reservas, mientras que por otro lado se colocaban títulos en el mercado local para evitar el efecto inflacionario que esas adquisiciones suponían por expansión de la masa monetaria. Asimismo creció el gasto por el repunte de la inversión pública facilitada por el ciclo económico expansivo, pero de todas formas limitada por el imperativo del superávit fiscal; se relanzó la promoción fiscal a las inversiones privadas de la industria exportadora; se recuperó la 
propiedad estatal de algunas empresas previamente privatizadas que incumplían sus proyectos de inversión; se asoció puntualmente el Estado a otras recuperadas por los trabajadores y finalmente, se trató de influir en la formación de los precios internos, tal como ocurriera con los acuerdos que el gobierno buscó realizar con las grandes empresas para contener la inflación, intento que no estuvo exento de tensiones y, en rigor, de previsibles decepciones. En definitiva, una intervención relativamente mesurada pero que contrastaba con lo sucedido en la década anterior y con el discurso siempre mediáticamente vigente de la ortodoxia liberal que, por otro lado, seguía dominando en la mayor parte del universo académico y en las prescripciones políticas que imponían los organismos internacionales de crédito por vía de la extorsión financiera.

En lo referido a esto último, la deuda externa se comportaba como una férula que limitaba los esfuerzos locales para salir de las profundidades de la recesión anterior y, en consecuencia, también se encararon en este aspecto algunas medidas que no hubieran figurado en la agenda de la década anterior pero que, en definitiva, estaban dando la nota de los límites a los que estaba llegando el capitalismo financiero en todo el mundo.

A comienzos del 2005 el gobierno inició el canje de bonos en circulación contra otros - una mitad consolidados en divisas y la otra en pesos indexados- con una quita del orden del 75 al 55\% por un monto de 81.800 millones de dólares que representaba más de la mitad de la deuda externa. La propuesta fue aceptada por el 76,15\% de los bonistas lo que significó un ahorro para el Estado de casi 43.000 millones de dólares. Esta quita no alcanzó a las deudas con los organismos multilaterales y los bancos comerciales con los que, en principio, se buscaría simplemente modificar los vencimientos. El paso siguiente consistió en la cancelación meses más tarde de la deuda con el FMI, algo que ya habían comenzado a hacer otros grandes deudores ante el reclamo perentorio de la institución dada la delicada situación financiera en que se encontraba, lo cual facilitó el posterior distanciamiento de éste del monitoreo de la política económica nacional, a pesar de las exigencias en contrario del sector financiero y de las empresas privatizadas cuyos deseos eran formalmente expresados por los acreedores del Club de París. A partir de 
ese momento, y gracias al incremento de las reservas del Tesoro, el gobierno nacional buscó entablar conversaciones para renegociar también esa deuda y obtener así un margen de mayor independencia en el trato con los grupos económicos que le estaban vinculados (algunos bancos y empresas privatizadas de servicios), algo que finalmente la crisis mundial en ciernes terminaría posponiendo.

De esa manera cambió el agobiante horizonte financiero del país -que sigue arrastrando una deuda que representa el $60 \%$ de su PBI (mientras que en el 2002 representaba el 155\% Fuente INDEC) -lo que fue posible gracias a que a partir de mediados del 2002 el país salió de la recesión e inició un ciclo de recuperación con tasas de crecimiento inéditas y que se prolongaría durante casi seis $a_{n}{ }^{6}{ }^{6}$. Este ciclo de crecimiento aparece como la contratara casi exacta de la recesión que precipitara la caída del anterior modelo de convertibilidad monetaria ${ }^{7}$.

De esa tumultuosa situación se salió combinando por un lado las posibilidades que ofrecían las nuevas condiciones macroeconómicas nacionales e internacionales con medidas de políticas sociales y económicas que, como vimos, no siempre contaron con el consenso de los sectores sociales medios y altos. En el plano nacional, la devaluación trajo aparejada una serie de modificaciones en las condiciones de producción con impactos variables según los sectores productivos. A la alteración de los precios relativos que significó un inicial deterioro del salario, se sumó el control oficial del precio de la energía y ambas cosas permitieron reducir los costos de producción. En la medida en que éstas tenían capacidad ociosa

6 Entre 2002 y 2008 el PBI pasó -a precios constantes de 1993- de algo más de 200 mil millones de pesos a casi 400 mil millones. Las reservas del Banco Central que alcanzaban los 10 mil millones de dólares al finalizar 2002, pasaron a 48 mil millones a fines del 2008.

7 Ésta se había prolongado desde 1998 y había llevado al país en el año 2002 a una crisis aún mayor que la que produjo la hiperinflación de 1989. En esas circunstancias, el corset de la convertibilidad monetaria que alentaba la deflación -al punto que cayeron incluso los salarios nominales- estalló bajo el peso del endeudamiento a que necesariamente llevaba para sostener la paridad con el dólar. La salida de esa situación con la retención de los ahorros, la devaluación y una explosión de la desocupación que ya se había instalado con tasas alarmantes desde mediados de la década anterior, dio lugar a la ya evocada conmoción social que reclamaba que se abandonaran los diktats del Consenso de Washington. 
y si eventualmente contaban posibilidades de colocar sus ventas en el exterior, el tipo de cambio las tornaba competitivas permitiendo aprovechar un ciclo internacional de incremento del volumen de la demanda y de los precios de las commodities motorizado por los mercados asiáticos ya desde finales del siglo pasado. Esta coyuntura facilitó a ese grupo de empresas, que por ser las más concentradas tienen también la mayor capacidad exportadora, la reabsorción del quebranto financiero en que quedaron al momento de la devaluación por tener pasivos en dólares y, en ciertos casos, les permitió afrontar incluso una expansión de su capacidad operativa.

Por su parte, los precios internacionales al trasladarse al mercado doméstico en el marco de la caída real del salario, debían producir necesariamente un impacto inflacionario y una situación de aguda penuria interna. Sin embargo eso no ocurrió no sólo por el recurso a los derechos de exportación, sino también porque la devaluación facilitó un proceso de sustitución de importaciones de productos manufacturados de la que participaron empresas de menor tamaño sin posibilidades de insertarse en el sector externo pero con efectos reales en la demanda de mano de obra. Esto mismo, a su vez, permitió absorber más rápidamente de lo esperado una parte significativa de la desocupación y progresivamente produjo un incremento de la participación de los salarios en el PBI, potenció la demanda interna y con ello traccionó también el crecimiento de la inversión de las firmas productoras de insumos industriales que veían abrirse una demanda local que en el período anterior se había reducido a niveles comparables a los de comienzos de la convertibilidad. Como veremos más adelante, el aumento de la participación de los salarios en el ingreso fue más el efecto del incremento del volumen del empleo - se paso de una catastrófica desocupación del $20,4 \%$ en 2003 a un $8 \%$ a mediados de 2008- que de la recuperación del salario, variable ésta última que, al mantenerse inicialmente deprimida, también explica que, al menos durante los tres primeros años posteriores a la devaluación, la temida explosión inflacionaria no haya tenido lugar.

El panorama resultaba igualmente alentador para la producción agrícola que, como el resto de las commodities conoció una fuerte expansión de la demanda mundial. Sin embargo la situación 
en este caso sería conflictiva ya que, desde las lejanas épocas del modelo de sustitución de importaciones industriales, se produce sistemáticamente una competencia entre la colocación de la producción en el mercado externo y la demanda interna. La burguesía agraria pampeana y los sectores medios vinculados a ella no estaban tan fácilmente dispuestos a renunciar a las ganancias extraordinarias que les generaba la devaluación de la moneda. La introducción de retenciones arancelarias y la cupificación ocasional de algunas exportaciones dieron lugar a la movilización más importante que el gobierno tuviera que enfrentar y que, a su vez, fue capitalizada por un amplio abanico de sectores opositores -a veces de características insólitas dadas sus distancias ideológicas entre sí-. La explosión de ese descontento vino a coincidir con la irrupción de la crisis internacional actual.

\section{La crisis del 2008}

La recuperación de la producción posterior al primer semestre de 2002 se produjo en un primer momento aprovechando la capacidad instalada ociosa, pero a partir del año siguiente la inversión bruta fija empezó a aumentar a ritmo sostenido, alcanzando su mayor dinamismo entre finales de ese año y comienzos del 2004. Desde entonces, si bien los valores tendieron a bajar, siguieron manteniéndose siempre por encima del $13 \%$ del producto hasta que prácticamente se frena a mediados del 2008, para caer desde el último trimestre de ese año, reflejándose al comenzar el año 2009 una tendencia similar en el PIB. Sin dudas la crisis mundial vino a interrumpir un ciclo de crecimiento de la inversión que desde el año 2003, a la salida de la gran crisis nacional que estallara a fines del 2001, había hecho remontar la evolución del PBI que alcanzaba así valores de crecimiento inéditos a lo largo del último siglo en torno al 8 y $9 \%$ anual. Durante el año 2009 las condiciones de la actividad económica permanecieron estables en los primeros dos trimestres comenzando un proceso de reactivación en los últimos meses. Las proyecciones para 2010 varían entre el 2,5\% fijado en la Ley de Presupuesto y se estiran al 7 \% según las expectativas del gobierno (Declaraciones del Ministro de Economía diciembre de 2009) 
La mencionada discusión que, aunque sordamente, se había instalado desde un principio entre los sectores de productores de granos exportables y el gobierno en torno al nivel de las tasas de retención y al reclamo de los primeros para una progresiva derogación del arancel, alcanzó su mayor virulencia en ocasión de la disparada especulativa de precios mundiales ocurrida entre finales del $2007 \mathrm{y}$ comienzos del 2008. El gobierno nacional dispuso en ese momento un sistema de tasas móviles que acompañarían la fluctuación de los precios tanto a la alza como a la baja. Las corporaciones de productores agrarios de la región pampeana respondieron con un conflicto que duró casi todo el año, reclamando activamente mediante movilizaciones, cortes de ruta y desabastecimiento, la derogación de los derechos de exportación lo que a su vez fue acompañado por amplios sectores de clase media, sobre todo descontentos con una política fiscal que había venido incrementando la recaudación y con una política social que era susceptible de sostener un aumento de la adhesión al gobierno de los sectores más desposeídos.

En el momento en que el gobierno sostiene ese conflicto con la burguesía agraria y con los sectores de la oposición que se encolumnan detrás de ella estalla la crisis mundial actual y comienzan a sentirse sus primeros efectos con el repunte de una sostenida fuga de capitales que ya llevaba un año, no tanto especulativos como ocurriera al comenzar el siglo, sino sobre todo por vía de las cuantiosas remesas que permitieron tanto el ciclo de crecimiento como el proceso de extranjerización al que había sido sometida las estructura productiva durante la década liberal. Entre 1993 y 2005 , el valor agregado de las empresas industriales y comerciales de capital nacional sobre las 500 más grandes del país pasó del 38 $\%$ al 14\% (BURACHIK, 2008). Si bien los giros no son exclusivamente producto de las corporaciones extranjeras - y cabe además señalar que algunas grandes empresas que se presentan como argentinas tienen sus sedes en el extranjero-, esta tendencia de la estructura los facilita aún más. Las remesas de utilidades comenzaron a aumentar desde mediados del 2007 y alcanzaron su techo en el último trimestre del 2008, cuando 8.400 millones de dólares salieron del país fundamentalmente hacia las casas matrices. Entre 2007 y el segundo trimestre del 2009 se perdieron en total uno 43 mil millones de dó- 
lares. Así y todo, al desacelerarse la tendencia a la extranjerización de la economía -ya por el descalce monetario ya por la recuperación estatal de algunos activos que habían sido privatizados durante la década anterior-, al frenarse el endeudamiento por la falta de crédito y al aumentarse la recaudación impositiva así como las reservas del Banco Central mediante la compra de dólares para mantener el tipo de cambio, el efecto de la fuga sobre la liquidez del mercado pudo ser controlado ${ }^{8}$.

El conflicto agrario se prolongaría todo a lo largo del año 2008 y continuaría teniendo secuelas durante el año siguiente. Las exportaciones de granos y sus derivados conforman un ítem tradicional de las ventas al exterior ${ }^{9}$ y dado el interés por embolsar las ganancias extraordinarias que resultan del incremento actual de su demanda mundial, los sectores más directamente involucrados -generalmente grandes y medianos productores- se mantuvieron en pie de guerra a pesar de las concesiones obtenidas. Esta situación fue propicia para que los partidos de la oposición -que venían perdiendo iniciativa y con ello presencia en las urnas- se asumieran como los defensores del único sector social que, según se sostenía, podía salvar al país de la crisis. La apuesta opositora precipitó a su vez la reacción de los sectores que no había visto con simpatía la reestatización de algunas de las empresas privatizadas durante la década anterior ni que se hubiesen replanteado las relaciones con el FMI cuando, al saldarse su deuda, Argentina se negó a seguir recibiendo sus misiones de monitoreo. En función de todo ello, se alimentó desde los medios de comunicación un discurso sobre el "riesgo país", la

8 La tendencia a la fuga de divisas, si bien se desaceleró nunca se detuvo. En esas circunstancias y, dada la caída del superávit fiscal, desde el Ministerio de Hacienda se comenzó a considerar la necesidad de recomponer las relaciones con los organismos internacionales de crédito ante la eventualidad futura de un "blindaje" al cual tal vez debiera recurrirse si se agudizara la crisis. Por esa razón, al finalizar el 2009, se destinó un tercio de las reservas de libre disponibilidad para pagar la mitad de los vencimientos de deuda del año siguiente sin necesidad de acudir a su total refinanciamiento. Es importante aclarar que en 2010 se concentra el mayor volumen de deuda dado que los compromisos para los años subsiguientes son menores debido al exitoso de canje de la deuda externo encarado en el año 2005.

9 El conjunto de los complejos oleaginoso, cerealero y bovino explica alrededor del $40 \%$ de las exportaciones argentinas. 
"pérdida de confianza" y la "inseguridad jurídica" que habrían sido las causas supuestamente evidentes de la fuga de divisas durante la crisis. Agréguese a esto la política de enjuiciamiento contra los militares acusados de haber violado los derechos humanos durante la dictadura que venía llevando adelante el gobierno, el manejo que se había tenido de la conflictividad social sin recurrir a la represión de los sectores populares, la posición contraria al ALCA y el acercamiento a las administraciones de centroizquierda de la región, para entender la irritación de los sectores que habían sostenido al modelo dominante de la década del 90. La concurrencia de la crisis mundial y de la movilización de los sectores agroexportadoras facilitaron la constitución de un frente opositor al gobierno que, más allá de su heterogeneidad, servía para recuperar algún protagonismo en vistas a las próximas elecciones legislativas que fueron adelantadas y que le costaron al gobierno la mayoría absoluta que hasta ese momento detentaba en ambas cámaras.

No obstante, y dada la nueva correlación de fuerzas, el manejo de la gestión económica y de los programas de ayuda social serían críticos para que el gobierno lograra transitar la crisis continuando las reformas sociales y económicas que había empezado a encarar. Más adelante desarrollamos estos tópicos, pero baste aquí con señalar que con esos mecanismos se logró estimular la producción, el consumo, el empleo y el nivel de la actividad económica afectada por la abrupta caída de las exportaciones. En cuanto a la política financiera, se buscó mantener baja la tasa de interés mediante diversos mecanismos del BCRA tendientes a aumentar la liquidez de los bancos, aunque de hecho fueron los pocos bancos públicos que quedaron después de la convertibilidad quienes abrieron sus carteras de préstamos, ya que los privados, al contrario, las redujeron y concentraron su negocio en los préstamo personales y las tarjetas de crédito.

Mientras tanto el manejo de la moneda siguió orientándose, como lo hacía ya desde un par de años antes de la crisis mundial, a anclar el tipo de cambio para evitar efectos inflacionarios. Esto último tiene desde luego una doble consecuencia: si bien por un lado trata de preservar los ya bastante menguados ingresos de los asalariados, por otro mina la única ventaja competitiva de la industria nacional justamente en un contexto de devaluación del dólar; 
aunque por cierto también hay que señalar que en simultáneo el peso se desvaloriza frente a otras monedas como el euro y, en particular, el real. A fin de compensar la relativa apreciación del peso, se aumentó la liquidez de la plaza liquidez en dólares reduciéndose los encajes de los depósitos en esa moneda y abriéndose líneas de prefinanciamiento a la exportación sobre el excedente prestable en dólares que tienen los bancos, lo que combinado con estímulos fiscales a nuevos proyectos de inversión, debieran generar condiciones financieras favorables a la producción.

Por otro lado, se sancionó una ley para exteriorizar las tenencias de bienes y de moneda nacional o extranjera que no hubiesen sido declaradas al 31 de diciembre de 2007, debiendo transferirse los montos líquidos a entidades bancarias nacionales sin necesidad de informar fecha de compra ni origen. Se calcula que entre las divisas tesorizadas y las que se encontrarían en el exterior se alcanzaría un monto equivalente a la deuda externa, o sea alrededor de 150 mil millones de dólares. El blanqueo buscaba recuperar al menos parte importante de ese dinero, orientándolo mediante una tasa de imposición actual diferencial que favorecía a la inversión no financiera, en particular a proyectos productivos. De hecho sólo ingresaron poco más de 4.500 millones y de ellos sólo el $4 \%$ provenían del exterior.

En otro plano, se extendió el sistema de intercambio en monedas locales entre los miembros del Mercosur, ampliando el acuerdo realizado en ese sentido con Brasil antes de finalizar el año 2008. De manera similar, se cerró un acuerdo con China para intercambiar hasta 10 mil millones de dólares en yuanes y pesos. Y, por último, aprovechando las bajas tasas de interés internacional, se intentó reabrir antes de finalizar 2009 el canje de deuda a quienes no la aceptaron en 2005, tal como se había empezado a proyectar al momento de estallar la crisis. A fin de mostrar voluntad de pago y obtener tasas relativamente bajas para los nuevos bonos, la iniciativa se acompañaba con la constitución de un fondo de garantía de 6 mil millones de dólares con parte de las reservas que por entonces ya casi alcanzaban los 50 mil millones. Como el procedimiento se realizó directamente desde el Ejecutivo, la oposición obstaculizó la operación ateniéndose a la interpretación de la Constitución 
que indica que los empréstitos con el exterior son materia de su competencia, aún si en rigor no se trataba en este caso de tomar deuda. La cuestión siguió por lo tanto irresuelta, pero muestra cómo la circunstancia de la crisis siguió siendo aprovechada los partidos opositores en la búsqueda ahora de espacios propios con vistas a las elecciones presidenciales del 2011.

También se tomaron una serie de medidas impositivas, algunas de ellas, como veremos más adelante, de importancia estructural, tal las referidas a la gestión de los aportes previsionales y otras, como las concernientes a la regularización de la recaudación de esos mismos aportes, de escasos efectos reales. Pero, aquí también, se recurrió a una batería diversificada de instrumentos con alcances extremadamente variables. En primer lugar, y dada lo neurálgico del tema no sólo en lo económico, sino muy particularmente en el plano político a causa del frente conflictivo con la burguesía agraria, cabe enumerar rápidamente una serie de medidas arancelarias.

Aparte de la creación de nuevas barreras para-arancelarias como el reforzamiento del régimen de licencias de importación no automáticas a la importación exceptuando a los sectores con proyectos de expansión de las exportaciones, lo que, desde luego, no dejó de producir tensiones con los socios del Mercosur, se aumentaron los impuestos internos y el IVA en algunos productos electrónicos, rebajándolos al mismo tiempo para los que se fabriquen en Tierra del Fuego con el fin de estimular la producción industrial. Pero el tema más álgido pasó naturalmente por los derechos a las exportaciones agropecuarias. Ante las dificultades políticas con el sector, como así también por efecto de la mayor sequía de las últimas décadas, se redujeron los aranceles a las exportaciones de trigo, maíz, frutas y hortalizas.

A la ya mencionada repatriación de bienes y capitales colocados en el extranjero y no declarados u ocultos en el país, que eran susceptible de mejorar la recaudación, se agregaron medidas tendientes a evitar la fuga de capitales y otras moratorias, sobre todo relacionadas con los aportes patronales con resultados igualmente limitados.

Pero la renacionalización del sistema previsional fue sin duda la medida de mayor impacto tanto a nivel fiscal, por lo que incide en la estructura presupuestaria y por sus consecuencias en la inversión 
pública, como a nivel social, por su directa relación con la distribución del ingreso. Por esta vía se logró hacer ingresar al sistema previsional una cantidad de pasivos que no habían alcanzado a jubilarse y se estableció un sistema automático de movilidad en los haberes, al tiempo que se recuperaba una importante fuente fiscal del orden de los 90 mil millones de pesos y una recaudación anual que ronda el $10 \%$ del PBI. Las consecuencias fueron numerosas ya que con esos fondos se sostuvo gran parte de las medidas de promoción económica que enunciáramos más arriba: obras públicas, participación en obligaciones privadas, subsidios a la vivienda, asignaciones de ingresos a la población con menores recursos, etc.

\section{La crisis, el empleo y el ingreso}

Entre el tercer trimestre del 2008 y el tercero de 2009 la desocupación pasó de 7,8 \% a 9,1\%, terminando un ciclo de seis años de caída ininterrumpida y reflejando así el impacto de la crisis sobre el empleo. A fin de enfrentar los efectos previsibles en este sentido, desde noviembre de 2008 el gobierno anunció la ejecución de un plan anticrisis. Las medidas adoptadas que ya detallamos más arriba asignaron $\$ 13.200$ millones al fomento de la producción y el consumo y destinándose también recursos para la actividad de las pequeñas y medianas empresas, de los productores agrarios y las producciones industriales tanto las mano de obra intensivas como las exportadoras. Otro pilar del plan fue la formulación de un Plan de Obra Pública, que demandaría 21.000 millones de dólares, esperando que se crearan de ese modo más de 300.000 empleos. Se procuraba de esta manera sostener tanto al mercado interno como a los mercados externos de manufacturas que se habían comenzado a abrir con anterioridad y, por ello, se mantuvo una política cambiaria que favoreciera la competitividad de las exportaciones.

La decisión de apuntalar el empleo se vio reflejada también en algunos programas específicos como el Plan Argentina Trabaja destinado a financiar la creación de cooperativas de trabajo orientadas generalmente a la producción de infraestructura local, o el fortalecimiento del ya referido "Programa de Recuperación Productiva" que subvenciona a las empresas en dificultades pa- 
gando un porcentaje del salario de sus trabajadores durante un período máximo de seis meses. De esta manera el aumento de la desocupación durante los años 2008 y 2009 sólo fue de un 1,3 \% y desde fines de 2009 se constataba, tomando la información de la Encuesta de Indicadores Laborales que se realiza en las empresas formales de las principales ciudades industriales del país, el inicio de un ciclo de creación de empleo registrado que se reflejará casi seguramente en una caída de la tasas de desocupación durante el primer trimestre del año entrante.

En lo referido al ingreso, la información disponible no permite hacer afirmaciones tan seguras ya que el relevamiento de precios que sirve para calcular la tasa de inflación ha sido seriamente cuestionado y esto afecta tanto a las cifras de pobreza -que oficialmente siguieron bajando a pesar del incremento de la desocupación- como a la evolución del salario real que, según las cifras publicadas por el Banco Central, habría continuado a incrementarse para alcanzar por fin durante el tercer trimestre del año pasado un nivel similar al que tuvo antes de la devaluación del 2001.

De todas maneras, también deben considerarse en los mecanismos que inciden en una mejor distribución de los ingresos las políticas de inclusión que hemos mencionado más arriba y que, además de las referidas a los planes asistenciales, tomaron al sistema previsional recuperado por el Estado como un elemento activo para ese fin. Como ya señaláramos rápidamente en el capítulo anterior, desde antes de la crisis se incorporaron al sistema más de dos millones de personas de las cuales, la mayor parte, no reunía todos los requisitos para acceder a la jubilación debido a la crisis estructural del empleo de los últimos 30 años y a la expansión de la informalidad. Además, a fines del 2009 se creó la Asignación Universal por Hijo que está financiada por la recaudación de los aportes previsionales, una medida destinada a luchar contra la pobreza, aun con la ambiguiedad que esto supone tanto en lo que respecta a la lucha contra la informalidad laboral, como en lo que hace a la justicia social del momento que el esfuerzo se hace con fondos de los trabajadores retirados y las contribuciones previsionales de los activos. Pero gracias a estos fondos se otorgó una asignación por hijo a quienes estaban desocupados o no tenían empleos formales, permitiendo 
que alrededor de 2,8 millones de niños y jóvenes, en principio en situación de pobreza, contaran con un ingreso monetario haciendo a su vez que más de cinco millones de personas reciban en sus hogares una suma mensual cercana a US 50 por hijo. Esta medida, si bien se cubre con los aportes destinados a los trabajadores jubilados, que muy lejos están de una remuneración satisfactoria, opera sobre la distribución del ingreso en la medida en que los hogares que la perciben se encuentran mayoritariamente incluidos en dos últimos deciles del ingreso. Por otra parte, al incidir en la reactivación del consumo se estima que su impacto sobre la actividad económica rondará el 1\% del PBI concurriendo también al crecimiento del mismo para el año 2010. Actualmente, y en coincidencia con lo observado en la recuperación del consumo durante el último trimestre del 2009 , la mayor parte de las proyecciones no oficiales comienzan a preveer un crecimiento del PBI entre un 4,5 y $5 \%$ pese a que texto de la Ley de Presupuesto estima un incremento del 2,5\%.

Creemos que es posible sostener que el impacto de la crisis internacional en Argentina no tuvo la dimensión que ocasionó en otros países fundamentalmente por encontrarse menos dependiente del crédito internacional y esto como consecuencia, en parte, de la crisis del 2001 y, sobre todo, por la forma como luego se optó por salir de la misma,. Sin embargo esto no quiere decir que sus efectos no se sintieron en la economía nacional. La continuidad del modelo económico implementado tiene dificultades que responden a distintos órdenes, algunas de ellas son previas a esta última crisis y son responsabilidad exclusiva de la política gubernamental, mientras otras se vinculan con la caída de la demanda internacional de la commodities producidas. Por otra parte también es posible plantear que la "sensibilidad" del sistema político argentino y la particular estructuración de distintos niveles de estatalidad (Nacional-provincial-municipalidad) constela un marco especial para el desarrollo del proceso económico en la crisis. Por ello es necesario detenerse en algunas de las dificultades y limitaciones que atentan contra el éxito del modelo económico que se viene implementado luego de la salida del modelo neoliberal. Nos detendremos particularmente en tres cuestiones: el ya referido cuestionamiento a la validez de la información estadística provista para evaluar la importancia real del proceso inflacionario que tiene 
lugar, la lentitud en la mejora de la distribución del ingreso y la puja distributiva entre la Nación y la Provincias.

En enero de 2007 se implementaron mecanismos de intervención en el Instituto nacional de Estadísticas y Censos (INDEC). Hasta ese momento los índices elaborados por el organismo gozaban de gran confiabilidad que se ve disminuida a partir de la divulgación de índices de precios que no reflejan la creciente inflación. Los indicadores surgidos a partir de la nueva administración comenzaron a proporcionar evaluaciones de inflación inferiores a los realizados por diversos institutos privados y a los que elaboran algunas provincias. Esta distorsión afectó también otros indicadores centrales de la economía y la administración pública tales como los índices de pobreza e indigencia o la evolución del salario real. A su vez determinados instrumentos financieros tales como los bonos de la deuda externa en pesos cuyo valor es actualizado por el índice inflacionario sufrieron gran quebranto.

La pérdida de confianza de agentes internos y externos fue lógicamente considerable. En este escenario el discurso opositor alertó aún más a los actores económicos y a la opinión pública en general enfatizando el deterioro institucional, la falta de seguridad jurídica y la imprevisibilidad de las políticas públicas. La implementación de cambios en el personal encargado de elaborar indicadores "sensibles" tales como el Índice de Precios al Consumidor (IPC) fue denunciada por el sindicato de los empleados desplazados y sospechada por analistas privados y por la oposición política de apuntar a morigerar el crecimiento por ajuste de capital de la deuda pública emitida en pesos indexados. El "costo político" de la intervención en el INDEC por parte del Poder Ejecutivo a través del Ministerio de Economía desde 2006 resultó, en consecuencia, muy grande. A falta de datos confiables sobre la inflación real se contraponen estimaciones privadas (nada neutras) y de organismos provinciales (gobernadas por dirigentes opositores que resultan menos neutras aún) que aumentan las cifras inflacionarias y que, por supuesto, configuran un horizonte de expectativas inflacionarias que no hace otra cosa que aumentar los precios.

Otro de los puntos salientes de este proceso es la lentitud con que tiene lugar la distribución del ingreso. La fuerte expansión 
económica del periodo 2003-2007, que en sus valores acumulados supera el $52 \%$, no fue distribuida de manera proporcional entre los distintos sectores sociales. Si bien la indigencia se redujo en un 67.3\% y la pobreza en un $50.7 \%$, el $20 \%$ de la población que corresponde a la de mayores ingresos se apropió del 50\% de los recursos gestados en dicho período y la población comprendida en los 7 últimos deciles se apropió apenas del 37.5\% (LOZANO, RAMERO \& RAFFO, 2007).

La creación de empleo es un factor destacable de este período pero los salarios no progresaron proporcionalmente al crecimiento económico. Otros autores matizan este diagnostico afirmando que “...en el marco del acentuado proceso de crecimiento que comienza en 2003 se registra una notable recuperación del salario real promedio y la ocupación de mano de obra... la recuperación de la ocupación y el aumento del salario real promedio no fueron resultado de la mano invisible del mercado sino de la política que adopto la actual gestión gubernamental en pos de la reactivación económica..." (BASUALDO, 2008, p.2-3). La consistencia entre ambas posiciones estriba en que una cosa es el crecimiento del empleo y los niveles salariales y otra el reparto global de los recursos generados por la actividad económica.

Por fin, la coparticipación federal de impuestos implica la transferencia de recursos entre distintos niveles gubernamentales (nación-provincias-municipios). Las distintas funciones que cumple el sector público requieren ingresos que son distribuidos teniendo en cuenta incumbencias específicas. Las fuentes tributarias generan naturalmente los recursos necesarios para financiar el funcionamiento del estado nacional, de las provincias y de las municipalidades. La centralización de la recaudación de muchas de ellas a través de una agencia federal específica (AFIP) -creada en la década de los 90- abre la tensión entre el estado nacional y las provincias por los criterios de distribución de los recursos (esto mismo sucede entre las gobernaciones de provincias y los departamentos que las integran). La coparticipación en la distribución de los ingresos es el mecanismo empleado. Ganancias, Ganancia Mínima Presunta y el impuesto al Cheque son algunos de los impuestos coparticipables más importantes. Hasta el año 2009 el producido por los llamados derechos de exportación o "retenciones" no era coparticipable ya 
que, como lo señala la misma Constitución, los recursos aduaneros son exclusivos de la Nación. En un escenario de conflicto con las dirigencias rurales, el Poder Ejecutivo resolvió hacer coparticipable los ingresos provenientes de la comercialización de la soja que es el producto más significativo y de mayor rentabilidad de las exportaciones agrícolas, cosa que, a pesar de no coincidir con la letra de la Constitución no suscitó objeciones por parte de la oposición, aunque la disminución del volumen de las exportaciones agropecuarias y la baja del precio internacional de los commodities achicó los montos a distribuir.

Los conflictos por la distribución de los recursos dan lugar a relaciones políticas y económicas no siempre simétricas entre el gobierno y los bloques provinciales que se configuran a partir de la disminución del porcentaje percibido por las provincias. En línea con esto se enmarca la creciente dependencia de muchas provincias del financiamiento que realiza el Gobierno Nacional. Resulta ilustrativo en este sentido que, mientras que la Ley de Coparticipación de 1988 establecía que a las provincias les correspondía el 55\% de lo recaudado, hoy reciben, como producto de un proceso que remonta ya a la época de Menem, cerca del 35\%.

Por otro lado, la desaceleración del crecimiento y por lo tanto la caída en la recaudación de ciertos gravámenes vinculados a ganancias y al consumo (en particular el IVA), provocó la necesidad de buscar fuentes alternativas de financiamiento. En este sentido el Gobierno utilizó recursos provenientes del sistema previsional y del PAMI - fondo de asistencia médica para los jubilados- con el objetivo de no desfinanciar estructuras estatales y de asegurar la continuidad de las políticas sociales y el mantenimiento del nivel de actividad económica. De esa manera, la reestatización del sistema previsional corre el riesgo de tornarse a la larga en un mecanismo de colocación de la deuda pública; por lo pronto, ya en la actualidad casi dos tercios del Fondo de Garantía del sistema previsional están compuestos por bonos del Estado. Esta puede llegar a ser una pesada caución sobre la actual gestión, aún cuando la reforma haya permitido revalorizar en lo inmediato el rol del Estado como regulador eficaz de la economía y garante de un mínimo de redistribución de la riqueza. 


\section{Consideraciones finales}

Por qué la actual crisis mundial económico-financiera -que es tan o más importante que la de 1929- impactó menos en Argentina de lo que lo hicieron otras crisis anteriores. El modelo económico desarrollado a partir del año 2003 permitió a la Argentina enfrentar la crisis económica internacional de una manera exitosa en la medida en que no se redujo su PBI ni debió realizar "ajustes" de alto costo social. Sin embargo, las nuevas condiciones internacionales hicieron que se desacelerara el ritmo de crecimiento que en el período 2003-2008 mantuvo en un promedio superior al 8,5\% anual.

Las políticas contracíclicas y el mantenimiento del equilibrio macroeconómico basado fundamentalmente en el superávit fiscal y el superávit comercial, brindó un amplio margen de maniobra mediante la utilización de tres mecanismos: la direccionalidad del gasto público, el impulso y la regulación del crédito (ambos destinados a estimular la demanda agregada) y el mantenimiento del tipo de cambio competitivo. Estos tres dispositivos fueron empleados para estimular el nivel de actividad.

Por otro lado Argentina no sufrió significativamente la merma del acceso al crédito internacional en la medida en que desde el default del año 2002 no contaba con este recurso. El relacionamiento con el FMI, con el Club de Paris y con los holdouts (Tenedores de bonos predefault que no participaron en el canje de la deuda externa llevado a cabo en el año 2005) han hecho que el riesgo-país fuera muy alto y por lo tanto se configuró un escenario anterior a la crisis internacional que impedía el acceso al crédito externo. Ese relativo aislamiento, que fuera presentado por algunos sectores económicos como una debilidad del modelo, hizo que el impacto de la crisis fuera mucho menor que en otros países altamente dependientes del crédito externo. Básicamente podemos decir que el mayor impacto de la crisis en la economía Argentina consistió en la caída del nivel de exportaciones y en la merma del precio de los principales productos que comercializa.

El nivel de reservas (al finalizar 2009 de aproximadamente en US 48.000 millones) y la flexibilidad del régimen cambiario permitieron el mantenimiento y la estabilidad de las variables ma- 
croeconómicas, evitando que la persistente salida de capitales se transformara en una crisis de balanza de pagos. A su vez, la flexibilidad de la política cambiaria dio lugar a una devaluación controlada sin consecuencias desestabilizadoras. Si bien la salida de capitales de los años 2008-9 fue estimada en u\$s 43.300 millones, el Banco Central sólo vendió u\$s 967 millones de sus reservas al sector privado en tal período. Ello implica que el BCRA "solventó" sólo el 2,2\% de la fuga de capitales privados de ese período, financiándose del flujo de divisas provenientes del superávit comercial.

Es aún objeto de discusión hasta dónde el actual modelo es una superación o una nueva fase del modelo neoliberal que se inauguró con la crisis de mediados de los 70 y que había hecho de la Argentina, y de muchos otros países de la región, una economía desguarnecida y sujeta los efectos "contagiosos" de la inestabilidad de los mercados mundiales. No obstante, y más allá de las interpretaciones a ese respecto, la orientación adoptada rompió con la hegemonía de aquel pensamiento único y, ateniéndose al menos a la manera como el país reaccionó en la actual crisis mundial, permitió contar con suficiente autonomía como para poder sortear exitosamente el impacto de las convulsiones que sistemáticamente afectan al capitalismo y que suelen reproducirse aún con mayor violencia en su periferia.

En el año 1995 Ignacio Ramonet, en pleno auge de neoliberalismo, publicó en Le monde Diplomatique un pequeño artículo llamado "El pensamiento único". En él señalaba con acierto que el mismo consiste en "La traducción en términos ideológicos con pretensión universal de los intereses de un conjunto de fuerzas económicas, en particular las del capital internacional" (RAMONET, 1995, p. 1). El "pensamiento único" se sustenta en una serie de enunciados/axiomas: la hegemonía absoluta de la economía sobre el resto de los dominios sociales; el mercado como mano invisible capaz de corregir cualquier tipo de disfunción social; a importancia de la competitividad; el librecambio sin límites; la mundialización, pero en su acepción económico-financiera; la división mundial del trabajo; la desregulación sistemática de cualquier actividad de carácter social; la privatización y, por fin, la conocida fórmula: "Menos Estado, más Mercado” (ALVAREZ DE SOTOMAYOR, 1999). 
El consenso logrado por estas afirmaciones referidas inicialmente al ámbito económico, pero que indudablemente lo exceden para brindar una propuesta general de organización de lo social y lo cultural, fue muy grande. En Argentina fue durante la década del los años 90, durante el período menemista que adquirieron mayor hegemonía ${ }^{10}$. Fue durante ese período que se aplicaron sin anestesia las políticas de liberalización de la economía, la privatización de las empresas públicas, la desregulación de los mercados, la apertura económica si ningún tipo de restricciones a la economía global y la reducción del Estado a su mínima expresión. Al decir de Ramonet "Ningún país, en ninguna parte del mundo, ha ido tan lejos en la aplicación del Consenso de Washington, ese pensamiento único neoliberal impuesto por el Banco Mundial y el FMI" (La voz de Galicia 8-01-2002). Los costos sociales de la aplicación de este modelo fueron enormes y desembocaron como hemos visto en la crisis económica y social de fines del año 2001.

A partir de ese traumático escenario la disputa cultural continuó siendo intensa pero se revalorizaron mecanismos e instrumento imprescindibles para el diseño de políticas. Concretamente, mutaron abruptamente las concepciones sobre el Estado, sobre el rol de los mercados, sobre los mecanismos de regulación y sobre la necesidad de configurar un patrón de acumulación que contemplara mayores niveles de participación e inclusión social. Estos cambios están planteados desde un paradigma que no cuestiona las bases del modelo capitalista de acumulación sino desde una posición que pretende rediseñar la forma general de la acumulación en un nuevo ciclo, privilegiando a sectores internos y condicionando la operatoria de los grupos económicos anteriormente privilegiados. La disputa de sentidos entre ambas posiciones no está resuelta ni mucho menos y tiene aún un final abierto.

Es por lo tanto difícil saber hoy con aproximación aceptable cuáles serán los verdaderos alcances de este modelo todavía en ciernes que, si bien pasó favorablemente la prueba de la actual crisis,

10 Alfredo Eric Calcagno y Alfredo Fernando Calcagno denominaron con humor a estas creencias económicas el "uni-verso neoliberal" (CALCAGNO \& CALCAGNO, 1995). 
no ha logrado aún consolidar su perfil ni, lo que es más grave, un sustento político de masas que lo reafirme. Se agregan a eso otros obstáculos de índole económica que no lograron superarse, tales como los vinculados a la fragilidad de su estructura productiva crecientemente apoyada en los ingresos provenientes de la explotación y la comercialización externa de los recursos naturales. La soja ha sido seguramente el producto más paradigmático de esta tendencia. La rentabilidad de este grano ha desplazado a otros cultivos, ha modificado las fronteras agrarias y ha generando no pocos problemas ecológicos, favoreciendo además procesos de concentración de la tierra. En torno a la soja, a su cotización no controlable desde el país -que en esta ocasión se conjugó con la mayor sequía de los último 50 años- y sobre todo a los intereses muy poderosos que a ella están vinculados, se desplegó el escenario de las disputas políticas locales que se desarrollaron justo en el momento de la crisis mundial. No deja de ser significativo - y sintomático de lo mucho que aún falta transitar para salir del modelo abierto en 1975- que un solo producto, por otro lado tan elemental, haya sido el ariete para atacar la capacidad del Estado de hacer pasar esta crisis prácticamente inadvertida.

Recebido em: 28.7.2010

Aprovado em: 06.9.2010

\section{Referencias}

ALVAREZ DE SOTOMAYOR REINA, C. (1999): Qué es el pensamiento único. INETemas Nro. 16. Córdoba. diciembre 1999.

BASUALDO E. La distribución del ingreso en la Argentina y sus condiciones estructurales. Buenos Aires: Centro de Estudios Legales y Sociales. Memoria Anual, 2008.

BONNET, A. Que se vayan todos. Crisis e insurrección en Argentina 2001, Bajo el volcán. Revista del Posgrado de Sociología de la BUAP 5: Puebla, pp. 36-62. mayo 2002.

BURACHIK, G.: Análisis de la encuesta a grandes empresas del INDEC, Realidad Económica Nro. 235, IADE: Buenos Aires, pp. 62-83, abril-mayo 2008. 
CALCAGNO, E. \& CALCAGNO, A.F. El Universo Neoliberal. Recuento de sus lugares comunes. Alianza Editorial: Buenos Aires, 1995.

Comisión Especial Investigadora de la Cámara de Diputados sobre Fuga de Divisas de la Argentina en el Año 2001: Fuga de divisas en Argentina. Informa Final. FLACSO/Siglo XXI: Buenos Aires, 2005.

LOZANO, C.; RAMERO, A \& RAFFO, T.: Crecimiento y distribución.

Notas sobre el recorrido 2003-2007. Instituto de Estudios y Formación CTA, Buenos Aires, 2007

RAMONET, I. La pensée unique. Le Monde Diplomatique, Paris, janvier 1995.

\section{Abstract \\ Effects of the global crisis in Post-Convertibility Argentina. Eco- nomic rationality under discussion}

Emerging from the repeated crises that Argentina has gone through over the last 35 years and particularly from the hyperinflation of 1989 came the neoliberal program that during the 1990s tied the country to a system of currency convertibility linked to the dollar. These measures opened the market to exportation, privatizing public firms, further expanding foreign debt and turning the country into an exemplary model for orthodox economic thought. Yet in 2001, a popular insurrection led to the model's collapse and created new conditions of governability. The economy was re-oriented and, in spite of opposition coming from several sectors, the country embarked on a new stage of unprecedented growth.

While this did not stop Argentina from becoming quite a bad example to follow, within the frame of reference of the global economy, the financial quarantine to which it was subjected preserved it from the worse effects of the 2008 crisis. This article looks at some elements that derive from this situation as well as the strong and weak points of current administrators. We seek attempt to use this opportunity to look at an experience that questions the parameters of the rationality that prevails in normative economic discourse.

Keywords: financial crisis, countercyclical measures, economic rationality. 